\title{
Pelatihan Pengenalan Aplikasi Perkantoran (Typing Master dan Microsoft Word) Bagi Remaja Karang Taruna RW. 08 Kelurahan Cinere Kecamatan Cinere Depok Jawa Barat
}

\author{
Endang Supriyadi ab,1, Maya Sofiana ${ }^{a b, 2}$, Rita Wahyuni ${ }^{\text {ab,3 }}$

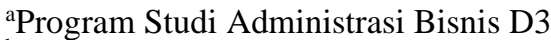 \\ bInstitut Ilmu Sosial dan Manajemen STIAMI Jakarta \\ 1endangs2013@gmail.com*_; maya72sofiana@gmail.com; ${ }^{3}$ rawahyuni@gmail.com \\ * corresponding author
}

\section{ARTICLE INFO}

Keywords

Karang taruna

Word

Typing master

\begin{abstract}
This training aims to improve the ten finger blind / blind system typing skill and be able to apply it to Microsoft Word application programs to be able to help quickly complete the administrative activities of the organization Karang Taruna RW.08 in the Cinere Sub-District Cinere Sub-District Depok West Java. By using the lecture method, practice and question and answer results in increased knowledge and understanding of youth youth related to material and practice as well as increased speed and accuracy in the process of making documents in Microsoft Word.

From the results of the community service activities, it can be concluded that the knowledge and understanding of youth in youth has increased.

Thus the skills of youth youth in utilizing the typing master application program and its application to Microsoft word also increased.
\end{abstract}

\section{PENDAHULUAN}

Kecamatan cinere merupakan salah satu kecamatan yang berada di wilayah depok dengan jumlah penduduk sebanyak 67.269 laki-laki dan 67.465 perempuan dari total jumlah penduduk kecamatan cinere sebanyak 13.4734 orang yang terdiri dari laki dan perempuan. Berikut ini statistic kondisi jumlah penduduk yang di release oleh BPS Depok. (DEPOK, 2016)

Tabel 1.

Jumlah Penduduk Menurut Jenis Kelamin

\begin{tabular}{|c|c|c|c|}
\hline \multirow[b]{2}{*}{ Kecamatan } & \multicolumn{3}{|c|}{ Jumlah Penduduk Menurut Jenis Kelamin (Jiwa) } \\
\hline & $\begin{array}{l}\text { Laki-laki } \\
2016\end{array}$ & $\begin{array}{c}\text { Perempuan } \\
2016\end{array}$ & $\begin{array}{l}\text { Laki-laki dan Perempuan } \\
\qquad 2016\end{array}$ \\
\hline Kota Depok & $1,098,473$ & $1,081,340$ & $2,179,813$ \\
\hline Limo & 55,823 & 54,452 & 110,275 \\
\hline Bojongsari & 63,508 & 61,539 & 125,047 \\
\hline Cinere & 67,269 & 67,465 & 134,734 \\
\hline Sawangan & 78,880 & 76,053 & 154,933 \\
\hline Cilodong & 79,183 & 77,559 & 156,742 \\
\hline Cipayung & 81,500 & 78,882 & 160,382 \\
\hline Beji & 105,331 & 102,678 & 208,009 \\
\hline Pancoran Mas & 132,807 & 131,135 & 263,942 \\
\hline Tapos & 136,242 & 134,848 & 271,090 \\
\hline Sukmajaya & 144,520 & 146,747 & 291,267 \\
\hline Cimanggis & 153,410 & 149,982 & 303,392 \\
\hline
\end{tabular}

Sumber : BPS Kota Depok 2016

Dari tabel 1. terlihat bahwa jumlah penduduk kecamatan cinere menempati peringkat ke 3 dibandingkan dengan kecamatan lain dari total jumlah penduduk di wilayah kota depok sebanyak 
2.179.813 orang baik laki-laki maupun perempuan. Sedangakan luas wilayahnya secara administratif $1104.1 \mathrm{~km} 2$ dengan kepadatan penduduk 11.790 jiwa tiap kilometer persegi. (Depok B. , 2016) Karang taruna RW.08 kelurahan cinere berada diwilayah kecamatan cinere depok memiliki tingkat populasi penduduk 43437 orang dan memiliki jumlah penduduk yang paling tinggi diantara ketiga kelurahan lainnya. Sebagaimana terlihat pada tabel 2 berikut ini :

Tabel 2.

Jumlah Penduduk Kecamatan Cinere Menurut Jenis kelamin tahun 2015

\begin{tabular}{|c|c|c|c|c|}
\hline NO & Kelurahan & laki-laki & perempuan & jumlah \\
\hline 1 & Cinere & 22012 & 21425 & 43437 \\
\hline 2 & Gandul & 16219 & 14954 & 31173 \\
\hline 3 & Pangkalan Jati baru & 6994 & 6809 & 13803 \\
\hline 4 & Pangkalan Jati & 13079 & 12543 & 25622 \\
\hline
\end{tabular}

Tabel 3.

Jumlah Penduduk Yang Memiliki

Pekerjaan Utama Tahun 2015

\begin{tabular}{|c|l|r|}
\hline No & Kelurahan & Bekerja \\
\hline 1 & Cinere & 34262 \\
\hline 2 & Gandul & 19932 \\
\hline 3 & Pangkalan Jati Baru & 7137 \\
\hline 4 & Pangkalan Jati & 21316 \\
\hline
\end{tabular}

Sumber : Kantor Kecamatan Cinere

Akan tetapi jumlah penduduk yang memiliki pekerjaan utama (petani, wiraswasta, UKM, buruh, PNS, TNI/Polri, pensiun, pedangang, dan lainnya) atau bekerja sebanyak 34.262 orang dari jumlah penduduk kelurahan cinere sebanyak 43.437 sebagaimana yang terdapat pada tabel 2 dan 3 . Sisanya yaitu sebanyak 9175 orang yang belum memilki pekerjaan utama.

Sehingga masalah yang dihadapi oleh kelurahan cinere adalah banyaknya jumlah populasi penduduk akan tetapi masih banyak memiliki penduduk yang belum memiliki pekerjaan. Oleh Karena itu pengabdian masyarakat berupa pelatihan soft skill yang dilaksanakan di wilayah kelurahan cinere khususnya karang taruna RW 08 dapat meminimalisir pengangguran dan memberikan peningkatan keahlian peserta sebagai bekal untuk menghadapi persaingan kerja di era informasi dan teknologi. (tjahjono, 2014)

\section{KAJIAN PUSTAKA}

\subsection{Karang Tarun}

Karang Taruna adalah organisasi kepemudaan di Indonesia. Karang Taruna merupakan wadah pengembangan generasi muda nonpartisan, yang tumbuh atas dasar kesadaran dan rasa tanggung jawab sosial dari, oleh dan untuk masyarakat khususnya generasi muda di wilayah Desa / Kelurahan atau komunitas sosial sederajat, yang terutama bergerak dibidang kesejahteraan sosial. Sebagai organisasi sosial kepemudaan Karang Taruna merupakan wadah pembinaan dan pengembangan serta pemberdayaan dalam upaya mengembangkan kegiatan ekonomis produktif dengan pendayagunaan semua potensi yang tersedia dilingkungan baik sumber daya manusia maupun sumber daya alam yang telah ada. Sebagai organisasi kepemudaan, Karang Taruna berpedoman pada Pedoman Dasar dan Pedoman Rumah Tangga di mana telah pula diatur tentang struktur penggurus dan masa jabatan dimasing-masing wilayah mulai dari Desa / Kelurahan sampai pada tingkat Nasional. Semua ini wujud dari pada regenerasi organisasi demi kelanjutan organisasi serta pembinaan anggota Karang Taruna baik dimasa sekarang maupun masa yang akan datang.

Karang Taruna beranggotakan pemuda dan pemudi (dalam AD/ART nya diatur keanggotaannya mulai dari pemuda/i berusia mulai dari 11 - 45 tahun) dan batasan sebagai Pengurus adalah berusia mulai 17 - 35 tahun. 


\subsection{Typing Master}

Menurut Rizaldy (Rizaldy, 2016) Typing master atau yang lebih dikenal dengan typing master pro adalah sebuah software yang dapat melatih kecepatan mengetik. Dengan software ini, dapat menjadi seorang pengetik yang handal. Typing Master ini dapat membantu siapa saja yang ingin belajar mengetik sepuluh jari tanpa melihat tombol keyboard. Selain itu, software atau aplikasi ini juga dilengkapi dengan berbagai macam permainan untuk meningkatkan kecepatan mengetik seseorang di setiap sesi pelajaran. Selain itu program typing master dapat melatih kemampuan mengetik dengan menggunakan teks yang telah disediakan serta dapat melihat hasil kemampuan mengetik, seperti kecepatan, keakuratan, dan durasi waktu yang digunakan, kemudian mencetaknya.

\subsection{Microsoft Word}

Microsoft Word atau Microsoft Office Word atau Word adalah perangkat lunak pengolah kata (word processor) andalan Microsoft. Pertama diterbitkan pada 1983 dengan nama Multi-Tool Word untuk Xenix, versi-versi lain kemudian dikembangkan untuk berbagai sistem operasi, misalnya DOS (1983), Apple Macintosh (1984), SCO UNIX, OS/2, danMicrosoft Windows (1989). Setelah menjadi bagian dari Microsoft Office System 2003 dan 2007 diberi nama Microsoft Office Word. Di Microsoft Office 2013, namanya cukup dinamakan Word (wikipedia)

Ada berbagai macam fungsi microsoft word adalah sebagai pengolah kata sehingga semua pekerjaan yang berhubungan dengan pengolahan kata dapat dilakukan dengan aplikasi ini seperti:

1. Membuat surat

2. Membuat tabel

3. Membuat tulisan dengan berbagai variasi (word Art)

4. Menyisipkangambar/logo

5. Bagan organisasi

6. dan membuat dokumen lainnya.

Dengan mengkombinasikan kedua aplikasi tersebut (Aplikasi typing master dan microsoft word) dapat membantu para peserta pelatihan untuk dapat mengerjakan semua aktifitas administrasi dalam organisasi karang taruna kelurahan cinere kecamatan cinere depok, dengan cepat dan tepat.

Selain itu kemampuan atau keterampilan mengolah kata juga dapat menjadi nilai tambah atau bekal bagi para peserta pelatihan sebagai nilai kompetensi (soft-skill) didunia kerja yang sangat membutuhkan SDM yang sangat mahir mengetik 10 jari dengan cepat dan tepat dalam pengolahan kata pada dokumen.

\section{a. Tujuan}

Tujuan pelatihan ini adalah untuk meningkatkan keterampilan mengetik sepuluh jari buta dan mampu menerapkannya program aplikasi microsoft word untuk menyelesaikan aktifitas administrasi organisasi Karang Taruna RW. 08 di Kelurahan Cinere Kecamatan Cinere Depok Jawa Barat.

b. Manfaat

Dengan adanya pelatihan ini diharapkan dapat meningkatkan pelayanan pemerintah dengan masyarakat khususnya dalam hal administrasi publik dengan cepat dan tepat. Sehingga berdampak meningkatkan kepuasan terhadap pelayanan masyarakat.

\section{Metode Pelaksanaan}

Metode yang digunakan adalah : (1). Metode Ceramah yaitu peserta diberikan pembekalan materi, (2) metode tanya jawab yaitu Peserta diberikan kesempatan untuk bertanya dan di jawab oleh tutor /trainer, (3) Praktek yaitu Peserta melakukan kegiatan praktek bersama-sama sedangkan tutor mendemonstrasikan materi yang dibahas. 


\section{Hasil dan Pembahasan}

Pelaksana dan peserta dalam kegiatan ini adalah tim dosen administrasi bisnis Institut STIAMI dan peserta dari kegiatan ini adalah anggota karang taruna RW. 08 di Kelurahan Cinere Kecamatan Cinere Depok Jawa Barat.

Pelatihan dilaksanakan setiap hari, mulai tanggal 25 - 28 Juli 2016, bertempat di Kantor Kelurahan Cinere. Dengan jadwal, hari senin-sabtu jam 14:00 - 17:00. Diluar jam tersebut tim narasumber memberikan pelatihan secara private bagi peserta yang berminat belajar lebih mendalam serta waktu kosong digunakan untuk mengeksplorasi kemampuan / keterampilan anggota karang taruna.

Proses Pelatihan diawali dengan melakukan persiapan yang dibutuhkan untuk melakukan praktek mengetik sepuluh jari buta dan penerapan teknik dasar pada Microsoft word. Adapun persiapan yang dilakukan oleh para peserta pelatihan adalah :

a. Menyiapkan komputer atau laptop yang akan digunakan dan memastikan kondisi peralatan tersebut baik,

b. Instalasi Typing Master Pro

c. Instalasi Microsoft Word ( jika belum tersedia )

d. Mempersiapkan modul praktek

e. Stopmap

f. Printer (sudah disiapkan)

Kemudian trainer memberikan penjelasan maksud dan tujuan yang ingin dicapai setelah mengikuti pelatihan dan menjelaskan waktu pelaksanaan serta materi yang akan disajikan pada program pelatihan tersebut.

Selama pelatihan berlangsung para peserta pelatihan mempraktekan semua teknik mengetik dan penerapannya pada Microsoft word sesuai dengan contoh yang sudah didemonstrasikan. Para peserta dapat melakukan pertanyaan disaat proses praktek berlangsung dan trainer membantu peserta yang mendapat kendala pada saat melakukan aktifitasnya.Kegiatan praktek setiap harinya memakan waktu selama 3 jam yang terdiri dari : 30 menit teori dan 2,5 jam praktek. Semua peserta mencetak hasil kerja mereka dari hari pertama hinggga hari terakhir dan dikumpulkan pada stopmap yang telah disiapkan.

Pada akhir pertemuan diadakan ujian secara tertulis dan praktek dengan tujuan agar para peserta pelatihan menguasi pengetahuan keterampilan pengolahan kata dan dapat mempraktekkannya pada saat melakukan kegiatan administrasi organisasi.

Berdasarkan wawancara, konsultasi dan pengamatan langsung selama kegiatan berlangsung, kegiatan pengabdian kepada masyarakat ini memberikan hasil seperti meningkatnya pengetahuan dan pemahaman remaja karang taruna terkait materi dan praktik serta meningkatnya kemampuan kecepatan dan ketepatan dalam proses pembuatan dokumen di Microsoft word.

Beberapa faktor yang mendukung terlaksananya kegiatan pengabdian pada masyarakat ini adalah besarnya minat dan antusiasme peserta selama kegiatan, sehingga kegiatan berlangsung dengan lancar dan efektif. Sedangkan faktor penghambatnya adalah semua peserta tidak seragam memiliki pengetahuan dan keterampilan yang sama serta memiliki background pendidikan yang berbeda.

\section{Kesimpulan}

Dari hasil kegiatan pengabdian pada masyarakat ini dapat disimpulkan bahwa pengetahuan dan pemahaman remaja karang taruna menjadi meningkat dan keterampilan remaja karang taruna dalam memanfaatkan program aplikasi typing master dan penerapannya pada Microsoft word semakin meningkat. Mengingat besarnya manfaat kegiatan pengabdian pada masyarakat ini, maka selanjutnya perlu diadakan sosialisasi dan pelatihan serupa pada remaja karang taruna kelurahan lain di Kecamatan yang lain, dengan materi yang sama dan menyediakan kesinambungan program pasca kegiatan pengabdian ini sehingga para remaja karang taruna benar-benar dapat mempraktekan keterampilan mereka.

\section{Saran}

Diharapkan dengan pelatihan yang telah diikuti oleh Karang Taruna RW. 08 di Kelurahan Cinere Kecamatan Cinere Depok Jawa Barat bersama tim dosen Prodi Ilmu Administrasi Bisnis Institut STIAMI tersebut dapat didukung oleh Kelurahan dan Disnaker setempat, agar remaja 
Karang Taruna RW. 08 di Kelurahan Cinere Kecamatan Cinere Depok Jawa Barat siap bersaing di Era Industri 4.0.

\section{UCAPAN TERIMA KASIH}

Ucapan terimakasih kami sampaikan kepada warga RW. 08 khususnya para remaja yang tergabung dalam karang taruna RW.08 Cinere Depok Jawa barat telah memberikan kesempatan kepada kami untuk melakukan kegiatan pengabdian masyarakat di wilayah kelurahan cinere khususnya warga karang taruna RW. 08 serta bantuan materil dan sprirtuil dalam pelaksanaan kegiatan pelatihan ini. Ucapan terima kasih kami sampaikan kepada pengelola jurnal yang telah mempublikasikan artikel kami. Terakhir, kami mengucapkan terima kasih kepada semua pihak yang telah membantu dalam kegiatan pelatihan dan penulisan artikel ini.

\section{DAFTRA PUSTAKA}

Depok, B. (2016). Kecamatan Cinere Dalam Angka 2016. Depok: BPS Kota Depok.

Depok, B. S. (2016, january 01). Penduduk Menurut Kecamatan dan Jenis Kelamin di kota Depok 2016. Retrieved january 2016, from BPS Kota Depok: www.depokkota.bps.go.id

katar08. (2014). Retrieved from http://katar08cinere.blogspot.com/: http://katar08cinere.blogspot.com/2014/12/anggaran-dasar-rumah-tangga.html

Rizaldy, R. (2016). Typing Master Pro. Retrieved 06 04, 2016, from http://magneticinfo.blogspot.co.id

tjahjono, b. (2014). Pelatihan Dasar Pengetikan dan MS-WORD untuk Karang Taruna Kelurahan Tanah Baru Kec. Beji Kota Depok. jurnal abdimas, 19.

wikipedia. (n.d.). Retrieved from https://id.wikipedia.org/wiki/Microsoft_Word 